\title{
Some aspects of large-scale travelling ionospheric disturbances which originate at conjugate locations in auroral zones, cross the equator and sometimes encircle the earth
}

\author{
G. G. Bowman and I. K. Mortimer \\ School of Mathematics and Physics, Physics Discipline, The University of Queensland, Brisbane, Queensland, Australia
}

Received: 13 April 2011 - Revised: 13 November 2011 - Accepted: 22 November 2011 - Published: 1 December 2011

\begin{abstract}
The occurrence of large-scale travelling ionospheric disturbances (LS-TIDs) has been examined. Initially some literature on their generation is considered. Travel during daylight hours and also paths which involve propagation paths towards the poles are illustrated by a few examples from the literature. A daytime ionogram recording of an LSTID is presented and discussed as are nighttime ionogram recordings for a poleward path of propagation. The tabulations of Moscow $h^{\prime} F$ recordings around midnight are examined for significant height increases which along with geomagnetic bays some hours earlier confirm the existence of LS-TIDs. A sunspot-maximum interval is involved. Some of the Moscow events were related to bays which occurred $32 \mathrm{~h}$ earlier thus indicating earth encirclements. Also additional encirclements are recorded by using superposed-epoch analyses for some other events.
\end{abstract}

Keywords. Ionosphere (Ionospheric disturbances; Ionospheric irregularities)

\section{Introduction}

Initially some early reports in the literature will be examined briefly on the generation of LS-TIDs. This occurs at times of intense auroral-zone absorption when substorms also occur. It was recently shown by Bowman and Mortimer (2010) that a significant number of large-scale travelling ionospheric disturbances (LS-TIDS) involve encirclements of the earth in about $30 \mathrm{~h}$. Some evidence for encirclements was earlier presented by Bowman (1965), where the use of ionograms suggests the occurrence of encirclements. Also a statistcal analysis involving 47 stations around the world indicated the existence of encirclements. The acronym EET was used for these earth encircling TIDs. The consequences of these encirclements will be considered in this paper. In the past most investigations of LS-TIDs involved the propagation from auroral zones (northern or southern) towards the equator. The acronym OHT will be used here for these one-hemisphere TIDs.

The existence of EETs means that some, if not all, of these LS-TIDs will cross the equator, and travel polewards. However all of these will not necessarily complete an encirclement. The EETs will also be involved with some travel in daylight hours. Figures 1 and 2 of Bowman (1978) and Fig. 1 of Bowman and Mortimer (2010) show that statistical analyses, involving over 300 substorm onsets, have shown that, for the equatorial movements, the average delay at the highlatitude station, Washington (geom. lat. 50.0), is $2 \mathrm{~h}$ and at the equator it is $4 \mathrm{~h}$. Using an estimated $6500 \mathrm{~km}$ for the distance from the auroral zone to the equator gives an average speed of $450 \mathrm{~m} \mathrm{~s}^{-1}$. This paper will also consider some aspects of the recent literature which concerns LS-TID events.

Tabulations of $h^{\prime} F$ for the high-latitude station, Moscow (geom. lat. 50.9), and for a sunspot-maximum interval, will be examined in a manner similar to that used by Bowman and Mortimer (2010) for Huancayo, (geom. lat. -0.6), The LS-TIDs will be identified using listings of Bays, which include substorm onsets. These will be used for analyses which concern the existence of EETs. Table 1 lists the geomagnetic coordinates of stations which will be mentioned and Table 2 explains the acronyms to be used. 

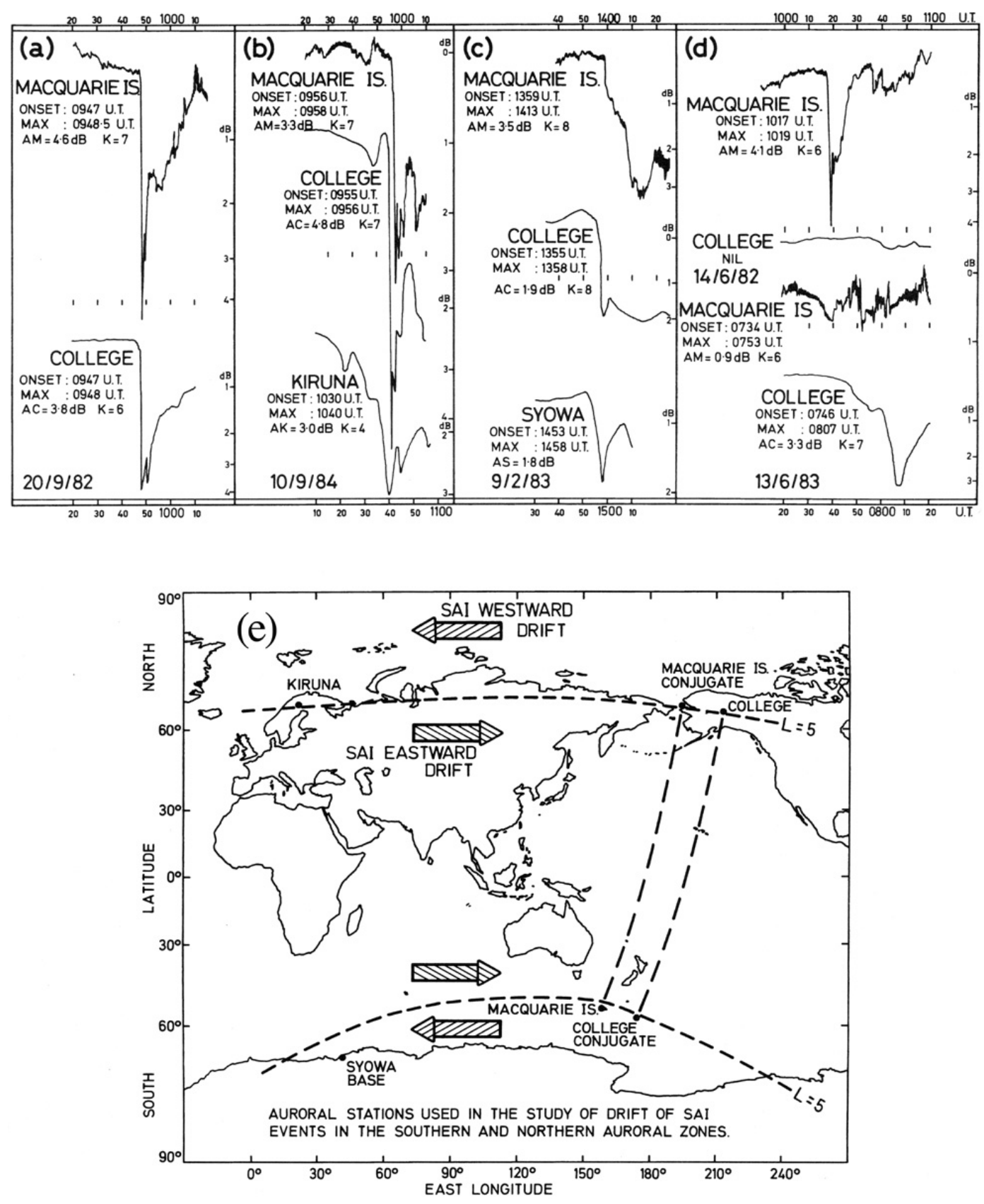

Fig. 1. Reproductions of Figs. 1 and 2 of Hajkowicz (1990), involving the conjugacy of auroral riometer absorption. Panels (a)-(d) illustrate examples of riometer absorption events at conjugate locations. Panel (e) illustrates the degree of conjugacy.

\section{Some aspects of LS-TID occurrence as detected in the literature, especially in the early reports}

\subsection{The generation of LS-TIDs and their initial equato- rial movements}

Early analyses by Hajkowicz (1983a) have shown that welldefined absorption events, at times of substorm onsets, are responsible for the generation of LS-TIDs at conjugate loca- tions (see also Hajkowicz, 1983b). These sudden absorption increase events (SAI events) are shown by Fig. 1ad, which is a reproduction of Fig. 1 of Hajkowicz (1990). This figure shows that the conjugate events occur at virtually the same time (x-axis), although their energy levels (y-axis) are slightly different. Hajkowicz (1983a) has summarized these observations by p. 1409 "The disturbances were consistent with the simultaneous occurrences of separate trains of large-scale ionospheric disturbances (TIDs) propagating 

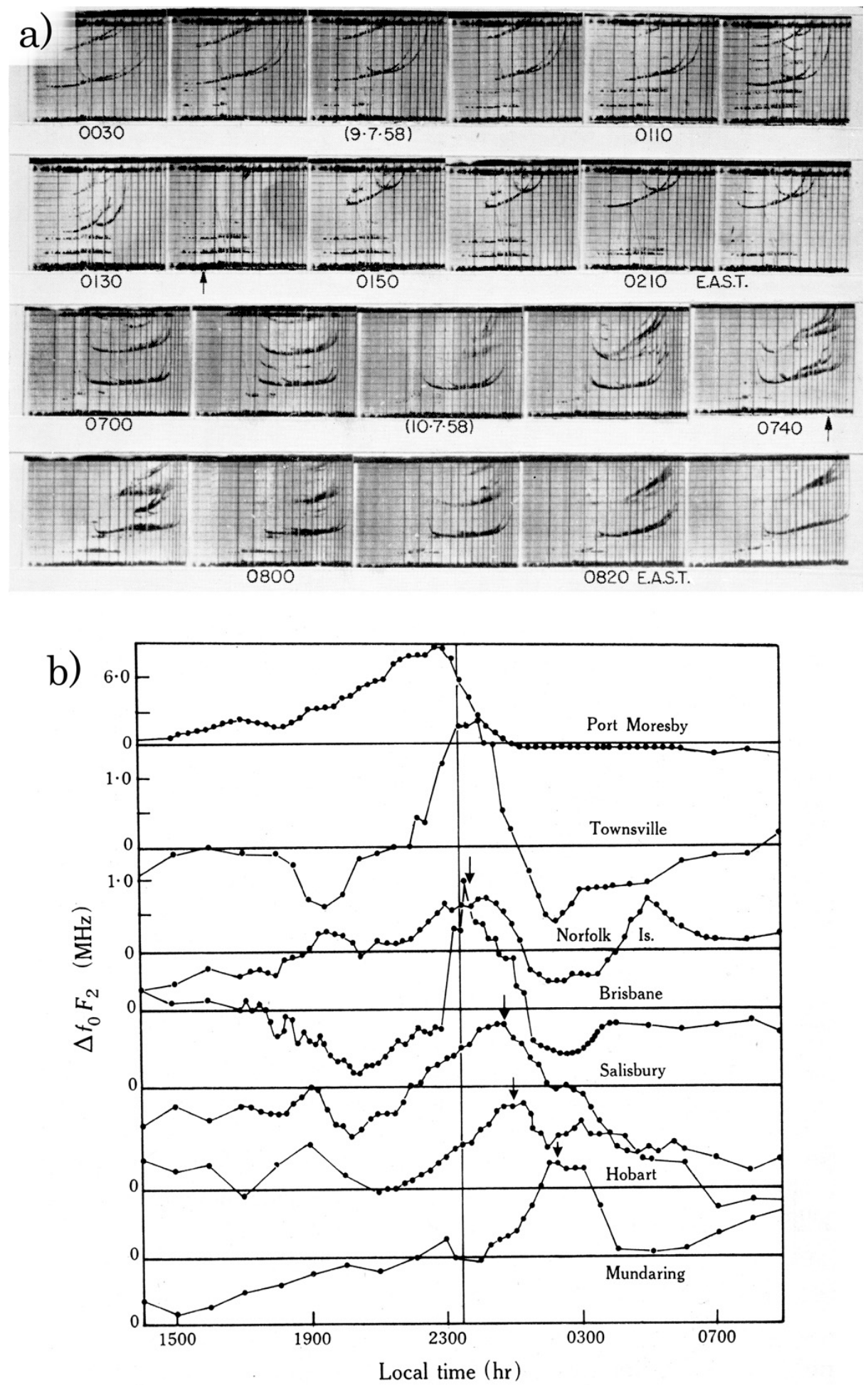

Fig. 2. (a) Reproduction of Fig. 8 of Bowman (1965), showing ionograms related to LS-TIDs recorded $30 \mathrm{~h}$ apart. It supports the other evidence by Bowman (1965) for encirclements, (b) a reproduction of Fig. 10 of Khan (1970).

equatorwards from the southern and northern auroral zones. It is suggested that TIDs were generated by an impulse-like increase in the conjugate particle precipitations inferred from the riometer records". Figure 1e, a reproduction of Fig. 2 of Hajkowicz (1990) for College and Macquarie Island, indicates the extent of their conjugacy. Hajkowicz (1983a) also 
Table 1. Geomagnetic coordinates.

\begin{tabular}{lrr}
\hline Station & Latitude & Longitude \\
\hline Barrow & 68.5 & 241.1 \\
College & 64.6 & 256.5 \\
Welen & 61.8 & 257.1 \\
Macquarie Island & -61.1 & 243.2 \\
Moscow & 50.9 & 120.5 \\
Washington & 50.0 & 360.2 \\
Brisbane & -35.7 & 226.9 \\
Maui & 20.9 & 268.1 \\
\hline
\end{tabular}

Table 2. Acronyms.

\begin{tabular}{ll}
\hline Abbreviations & Meanings \\
\hline EET & Earth encircling TID \\
OHT $_{\mathrm{a}}$ & One hemisphere TID by itself \\
OHT $_{\mathrm{b}}$ & One hemisphere TID and an EET \\
LS-TID & Large-scale travelling ionospheric disturbance \\
AGW & Atmospheric gravity wave \\
LSS & Large-scale structure \\
SAI & Sudden absorption increase \\
$\Delta h^{\prime} F_{\mathrm{a}}$ & Height changes relative to medians \\
$\Delta h^{\prime} F_{\mathrm{b}}$ & Height changes relative to 200 km levels \\
$\mathrm{UA}-\mathrm{NPD}$ & Upper-atmosphere neutral particle density \\
\hline
\end{tabular}

identifies an area near College as the site of generation of an LS-TID. Recently Ding et al. (2007) have also identified an isolated LS-TID source.

Of all the directions of travel LS-TIDS can take, north/south propagation is often detected by ionograms. For two particular LS-TID events the travel times, measured from the two auroral zones to the equator, can be compared. For each event somewhat different speeds have been measured. Figure 3 of Hajkowicz (1983a) shows that for a number of stations, at different latitudes in Japan and New Zealand, LS-TID speeds of $560 \mathrm{~m} \mathrm{~s}^{-1}$ and $630 \mathrm{~m} \mathrm{~s}^{-1}$, respectively, were found. Similarly for another event Bowman (1992a) has used stations in Japan and Australia to find speeds of $443 \mathrm{~m} \mathrm{~s}^{-1}$ and $507 \mathrm{~m} \mathrm{~s}^{-1}$, respectively (see Fig. 2 of Bowman, 1992a). These measurements were made using ionograms. If the distance between auroral zones and the equator is estimated to be $6500 \mathrm{~km}$ for the speeds recorded by Hajkowicz (1983a) the travel times for Japan and New Zealand were $3.2 \mathrm{~h}$ and $2.9 \mathrm{~h}$, respectively. For the event analysed by Bowman (1992a) the travel times for Japan and Australia were $4.1 \mathrm{~h}$ and $3.6 \mathrm{~h}$, respectively. These figures show that the travel times to the equator from the two auroral zones can be, for most purposes, considered as virtually the same, at least for these two events. Disturbance conditions at the equator can be expected to be enhanced.
Table 3. Geomagnetic indices, K and Kp (26 October 1968).

\begin{tabular}{ll}
\hline Whalen & 00331132 \\
College & 00340021 \\
Barrow & 12552243 \\
World (Kp) & 10121132 \\
\hline
\end{tabular}

\subsection{Some recordings of daytime LS-TIDs, and the pole- ward propagation of both daytime and nighttime events}

Table 3 of Bowman and Mortimer (2010) shows statistically the F2 layer changes during the passage of atmospheric gravity waves (AGWs) and the generation of LS-TIDs. The layer is first depressed and then enhanced. These enhancements which have periodicities of $30 \mathrm{~min}$ or more, have been used to track LS-TIDs. Figure 2a is a reproduction of Fig. 8 of Bowman (1965) and illustrates the nature of ionograms which record daytime LS-TIDs. Distorted traces similar to those recorded for medium-scale travelling ionospheric disturbances (see e.g. Heisler, 1963, and references therein) are present on the daytime ionograms. The $f o \mathrm{~F} 2$ fluctuations, which also occur over periods of $30 \mathrm{~min}$ or more, constitute large-scale structures (LSSs) and can be positive or negative as is shown by Fig. 7 of Karpachev et al. (2007). These foF2 changes have been used by investigators to detect LS-TIDs by using TEC perturbations, recorded by satellites, particularly during daylight hours.

A recent paper by Ding et al. (2008) mainly on daytime LS-TIDs during magnetic storms, will be considered in some detail here. Ding et al. (2008) state [1] "Of the 135 LS-TID events, 35 cases $(26 \%)$ occurred in the nighttime with their possible source within the region of North America, according to the variation of magnetic $\mathrm{H}$ component observed in this region. In addition, the occurrence of LS-TIDs peaks at 12:00 LT and at 19:00 LT." The positive and negative perturbations of TEC recordings over North America were used between 2003 and 2005 . The mean velocity was $300 \mathrm{~m} \mathrm{~s}^{-1}$ and the directions of travel varied from approximately south to south west, as their Fig. 1 shows. Figure 5a is the other figure of particular interest recorded by Ding et al. (2008). It shows, for the 100 daytime events, occurrence peaks around midday and the pre-sunset interval. During relatively quiet times, 14 daytime events were recorded with an average velocity of $233 \mathrm{~m} \mathrm{~s}^{-1}$. All of these were recorded around midday.

Since it is now known that LS-TIDs encircle the earth, they will at times propagate during daylight hours. Ding et al. (2007) have used satellite recorded TEC perturbations for daytime events. It is of interest to know how ionograms record these events. Figure 2a shows, for Brisbane, the recording of possibly an LS-TID event which encircles the earth in $30 \mathrm{~h}$ (see arrows on Fig. 2a). This occurs from 

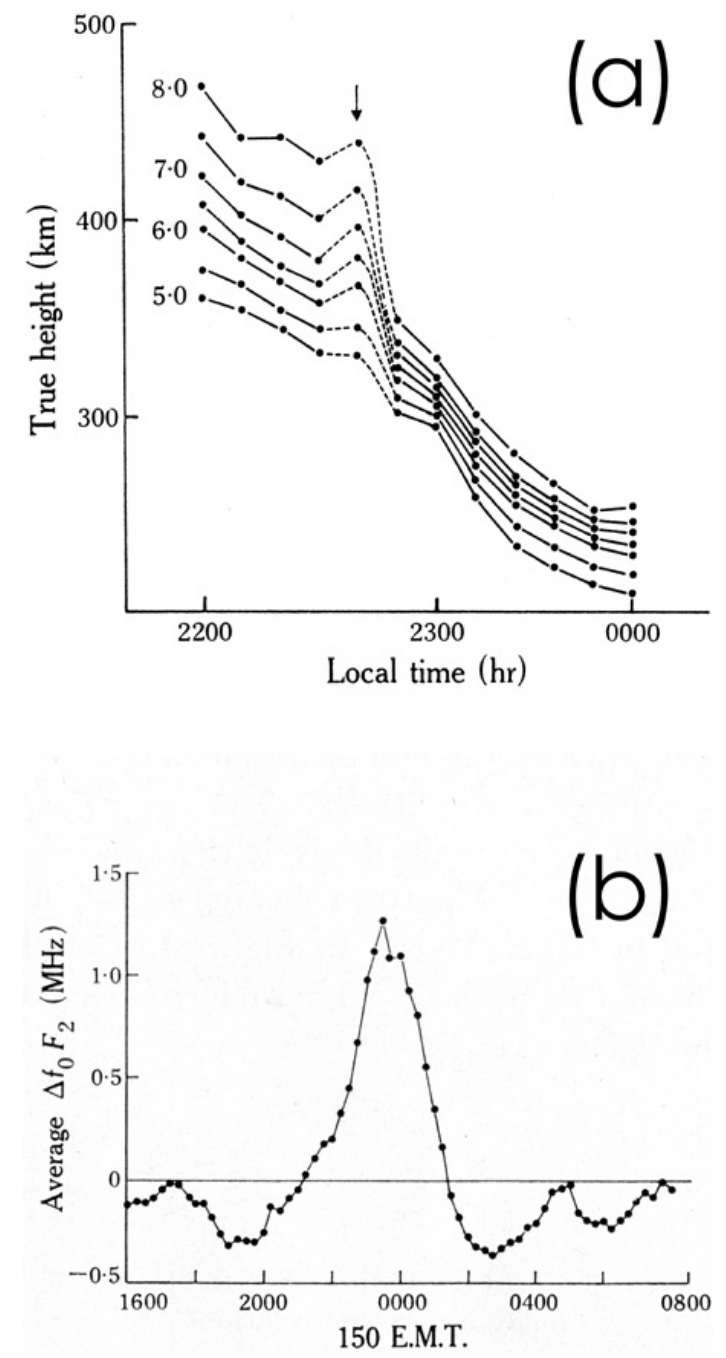

Fig. 3. From Khan (1970) reproductions of (a) Fig. 8 showing height changes and (b) Fig. 12 involving foF2 changes, both (a) and (b) associated with the LS-TID, shown by Fig. 2 b.

01:40 LT on 9 July 1958 to $07: 40$ LT on 10 July 1958 . The daytime event shows distorted ionogram traces, off-vertical traces at 07:30, 07:40 and 07:50LT. Sporadic E is recorded at 07:50 and 08:00 LT. There are no height rises of the main trace, as occurs during night hours.

An early paper by Chan and Villard (1962) reports the results obtained using ground-based radio-wave transmissions of about $20 \mathrm{MHz}$, over a period of 1 year. Nine LS-TIDs were detected over North America during daylight hours and travelling equatorwards. Recently Lei et al. (2008) reported on an investigation into LS-TIDs which were detected over Japan during the geomagnetic storm of 15 December 2006. The analyses used GPS TEC fluctuations and other data. Lei et al. (2008) state [1] "A prominent northward propagating large-scale traveling ionospheric disturbance (LS-TID) during daytime, seen by the GEONET total electron content
Table 4. LS-TID event at MAUI (26 October 1968).

\begin{tabular}{ccccccccc}
\hline \multicolumn{1}{c}{0} & \multicolumn{8}{c}{$h^{\prime} F$ levels - UT } \\
05 & 06 & 07 & 08 & 09 & 10 & 11 & 12 & 13 \\
\hline 219 & 226 & 217 & 204 & 235 & 230 & 219 & 245 & 223 \\
\hline
\end{tabular}

(TEC) data, was captured by the CMIT model". Besides this poleward propagating LS-TID, two other events were found which were travelling towards the equator.

Khan (1970) used results recorded by seven SouthernHemisphere ionosondes to investigate a nighttime disturbance which propagates towards the pole. Khan (1970) identifies this disturbance as a large-scale travelling ionospheric disturbance (LS-TID) in the F2 layer moving in a south-west direction with a velocity of $350 \mathrm{~m} \mathrm{~s}^{-1}$. It was noted that geomagnetic activity was low. Figure $2 \mathrm{~b}$ is a reproduction of Fig. 10 of Khan (1970) and shows the changes to $\Delta f o \mathrm{~F} 2$ data at the various stations for the travelling disturbance. At Brisbane, one of the stations, there are also associated $\Delta f o \mathrm{~F} 2$ fluctuations and a ground-based mircrobarograph disturbance, as Fig. 5c of Khan (1970) shows. Bowman and Shrestha (1966) reported the existence of an association between the occurrence of LS-TIDs and ground-level fluctuations recorded by microbarographs. Also at Brisbane, the F2 layer height changes, which are mainly decreases, are shown by Fig. 3a which is a reproduction of Fig. 8 of Khan (1970). The positive $\Delta f o \mathrm{~F} 2$ for six of the stations were averaged relative to Brisbane time, and the results are shown by Fig. 3b, a reproduction of Fig. 12 of Khan (1970). It seems likely that the observed $\Delta f o \mathrm{~F} 2$ increases are a consequence of the $h^{\prime} F$ decreases.

The disturbance shown by Fig. $2 \mathrm{~b}$ can, by further experimental evidence, be identified as an LS-TID. Although at the time of recording, world wide the geomagnetic activity is low, nevertheless, over a restricted region of the earth, it is enhanced for a certain period. In particular three stations on the Alaskan peninsula, College (geom. lat. 65), Whalen (geom. lat. 61) and Barrow (geom. lat. 69), record increased activity at this time. Table 3 lists the $\mathrm{K}$ indices for these stations on 26 October 1968, and indicates the sudden increases in geomagnetic activity commencing at 06:00 UT. An LSTID generated at this time might be expected to arrive at the low-latitude station, Maui, a few hours later. The $h^{\prime} F$ tabulations for Maui show that on 26 October 1968 the height increases at 09:00 UT, as is shown by Table 4 . Figure $2 \mathrm{~b}$ indicated that at the mid-latitude station, Brisbane, the disturbance arrives around 23:00 LT, which converts to 13:00 UT. This time suggests that the LS-TID has crossed the equator propagating towards the south pole, with a velocity of $350 \mathrm{~m} \mathrm{~s}^{-1}$. 
Table 5. Bays, associated or not, with $\Delta h^{\prime} F_{\mathrm{a}}$ events (number of occurrences, 1958-1960).

\begin{tabular}{ll}
\hline (a) No associated bays & 65 \\
(b) $\mathrm{OHT}_{\mathrm{a}}$ & 52 \\
(c) $\mathrm{OHT}_{\mathrm{b}}+\mathrm{EET}$ & 20 \\
(d) EET only & 35 \\
\hline
\end{tabular}

Table 6. Encirclement times.

\begin{tabular}{lccccccccc}
\hline Times (hours) & 26 & 27 & 28 & 29 & 30 & 31 & 32 & 33 & 34 \\
Occurrences & 0 & 3 & 1 & $\mathbf{1 4}$ & $\mathbf{1 1}$ & $\mathbf{1 7}$ & 7 & 2 & 0 \\
\hline
\end{tabular}

\section{Encirclements of one-hemisphere TIDs}

Similar to the analyses used for pre-sunrise $h^{\prime} F$ increases at Huancayo by Bowman and Mortimer (2010), here $h^{\prime} F$ tabulations for Moscow have been used for the $R_{\mathrm{Z}}$ max period 1958-1960. Over a three-hour interval (INTA), centered on local midnight, $h^{\prime} F$ levels $\geq 40 \mathrm{~km}$ of the median of each of the three hours are considered, and the highest value for the three is designated for the interval. The local time (LT) at Moscow is $2 \mathrm{~h}$ ahead of universal time (UT) and, as Table 1 shows, its latitude is similar to that of Washington. The INTA interval involves 21:00, 22:00 and 23:00 UT. Most of the $h^{\prime} F$ highs can be shown to relate to geomagnetic bays at appropriate earlier times thus indicating that these Moscow events are associated with the propagation of LS-TIDs. Bays listed for a $R_{\mathrm{z}}$ max interval have been used (see Bartels et al., 1962-1964). These $h^{\prime} F$ events were matched against bays which occurred either $2 \pm 1 \mathrm{~h}$ earlier or $32 \pm 2 \mathrm{~h}$ earlier. These longer intervals were used to detect LS-TIDs which encircle the earth. There were 172 height-increase events (the abbreviation $\Delta h^{\prime} F$ will be used). For this association with bays, these events were divided into four groups which are shown by Table 5, with an abbreviation appropriate for each group. These groups were (a) no associated bays, (b) bays identified a few hours earlier, (c) bays for both approximately $2 \mathrm{~h}$ and $32 \mathrm{~h}$ earlier and (d) bays for approximately $32 \mathrm{~h}$ earlier only. Each $\Delta h^{\prime} F_{\mathrm{a}}$ event was identified for one of the hours of INTA, and the hour of the related bay was also noted. Thus the times for the encirclements can be determined for the 55 EET events. The number of occurrences for these encirclement times are listed by Table 6 . Most of the encirclement times are recorded as 29,30 or $31 \mathrm{~h}$, as is expected.

The encirclement times shown by Table 6 involve bays which occurred many hours before the $\Delta h^{\prime} F_{\mathrm{a}}$ events. Analyses here have considered whether or not some of the LSTIDs, generated a few hours earlier and identified as $\mathrm{OHT}_{\mathrm{a}}$ events, (see Table 5), also encircle at later times. Superposedepoch analyses have examined the statistical significance of any results. However, as Tables 7 and 8 show, 4 encirclements of this kind have been found. For the analyses an-

\section{ENCIRCLEMENTS}

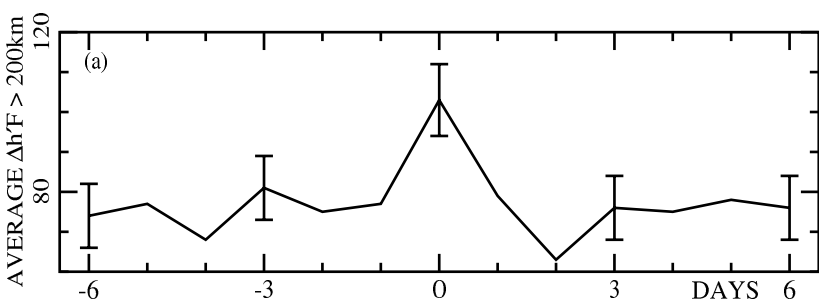

1959 and 1960 ENCIRCLEMENTS

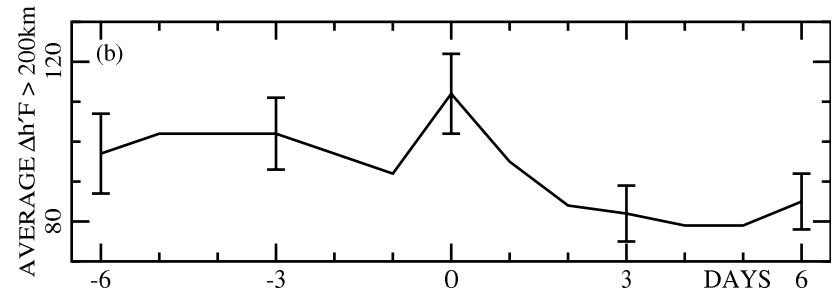

Fig. 4. Superposed-epoch analyses have been used for the Moscow $\mathrm{OHT}_{\mathrm{a}}$ events. The centre times indicates $\Delta h^{\prime} F$ increases $30 \mathrm{~h}$ after the Moscow events. Average $\Delta h^{\prime} F$ displacements for times $6 \mathrm{~h}$ before and after the $30 \mathrm{~h}$ events are also shown. (a) 1958 and (b) 1959 and 1960.

other interval of the three hours (INTB) is used with a centre hour (04:00 UT) $30 \mathrm{~h}$ later than the centre hour of INTA (22:00 UT). Thus INTB involves 03:00, 04:00 and 05:00 (UT). Each $\Delta h^{\prime} F_{\mathrm{a}}$ event associated with an $\mathrm{OHT}_{\mathrm{a}}$ event was used to select the highest $\Delta h^{\prime} F_{\mathrm{b}}$ value from one of the three INTB hours. Finally an average value for the 51 events is determined along with the average $\Delta h^{\prime} F_{\mathrm{b}}$ values for 6 days before and 6 days after for the one particular hour chosen for the highest $\Delta h^{\prime} F_{\mathrm{b}}$ value. The results are shown by Fig. $4 \mathrm{a}$ for 1958 and Fig. 4b for 1959 and 1960. The centre date for 1958 is statistically significant, while for Fig. $4 \mathrm{~b}$ the statistical significance is not as large. The average sunspot number for 1958 was 158 whereas for 1959 and 1960 it was 135 . This suggests that for 1958 the LS-TID energies will be greater, leading possibly to more encirclements.

\section{Discussion and conclusions}

Some of the literature, which reports on daytime LS-TIDs or those which cross the poles, has been examined. It seems likely that LS-TIDs regularly cross the equator. A paper by Bowman and Mortimer (2010) has considered LS-TIDs which sometimes encircle the earth. The tabulations of $h^{\prime} F$ for the high-latitude station, Moscow, are used here for analyses involving not only their detection using bays but also the possibility of encirclements. Of revelance to encirclements, Francis (1975) reports that LS-TIDs p. 1011 “......propagate freely to large horizontal distances with no loss of amplitude”. Further he also states, again p. 1011 “......even 
Table 7. LS-TID encirclements (MOSCOW - 1958 - UT).

\begin{tabular}{llccccccccc}
\hline \multirow{2}{*}{ Bay events } & \multirow{2}{*}{ EET events } & 00 & 01 & 02 & 03 & 04 & 05 & 06 & 07 & 08 \\
\hline (a) 2000 JAN 13 & 0500 JAN 15 & 325 & 280 & 240 & 215 & 235 & 260 & 245 & 230 & 245 \\
(b) 2100 FEB 12 & 0300 FEB 14 & 340 & 290 & 270 & 310 & 250 & 265 & 250 & 245 & 230 \\
(c) 2000 FEB 20 & 0300 FEB 22 & 350 & 310 & 320 & 350 & 320 & 250 & 250 & 250 & 240 \\
(d) 2100 MHR 3 & 0300 MAR 5 & 330 & 320 & 305 & 380 & 260 & 250 & 245 & 230 & 230 \\
\hline
\end{tabular}

Table 8. Around the world travel times at Moscow (1958).

\begin{tabular}{lcc}
\hline Bays & from Bays & from Moscow \\
\hline (a) 13 Jan 2000 & $33 \mathrm{~h}$ & $31 \mathrm{~h}$ \\
(b) 12 Feb 2100 & $30 \mathrm{~h}$ & $28 \mathrm{~h}$ \\
(c) 20 Feb 2000 & $31 \mathrm{~h}$ & $29 \mathrm{~h}$ \\
(d) 3 Mar 2100 & $30 \mathrm{~h}$ & $28 \mathrm{~h}$ \\
\hline
\end{tabular}

spherically spreading gravity waves observed at fixed height can appear to grow as they travel away from their source. The Earth's curvature presents no barrier to long distance propagation of such waves because they are refracted around the Earth by the gravitational field". Some daytime ionograms which record an LS-TID are shown as part of Fig. 2a. Also Fig. 2b illustrates nighttime ionograms for an LS-TID which is propagating polewards. The range spread seen on nighttime ionograms is not seen on daytime ionograms due to small AGW amplitudes. This can be explained by UANPD levels which maximize during the day (see Fig. $4 \mathrm{~b}$ of Bowman, 1991, 1992b). As Fig. 2a shows, daytime LS-TID ionograms do not record height increases. It seems likely that LS-TID height increases are also influenced by UA-NPD levels, as do the wave amplitudes which are responsible for spread-F traces on ionograms.

As their Fig. 5 shows, Ding et al. (2008) record that NorthAmerican daytime LS-TIDs occur, for 100 events, around two particular time intervals. One interval is centred on midday in addition to $2 \mathrm{~h}$ before and after. The other interval is most prominent at 19:00 LT with high occurrence $1 \mathrm{~h}$ before and $2 \mathrm{~h}$ after. The second peak around 19:00 LT occurs about $8 \mathrm{~h}$ after the midday peak. It is suggested that these two groups of maxima result from LS-TIDs generated at both northern and southern auroral zones on the nightside after they travel via the north pole. As an example consider the generation of an LS-TID on the nightside by a substorm-onset in the early evening hours or somewhat earlier. If propagation occurs via the north pole, from the northern auroral zone, the LS-TID can be expected at a NorthernAmerican station several hours later. On the nightside the time of arrival could be around midnight. For the station on the dayside this time will be around midday, as the two sides will be separated by about $180^{\circ}$ of longitude. The maxima around 19:00 LT can be explained by considering propagation to North America from the southern auroral zone via the north pole, As Fig. 1b of Bowman and Mortimer (2010) shows the travel time from a zone to the equator is $4 \mathrm{~h}$, so that between zones it is $8 \mathrm{~h}$. Furthermore Ding et al. (2008) find that twice as many events are recorded around midday than around 19:00 LT. Also they find for 14 events during quiet geomagnetic activity the average speed was $233 \mathrm{~m} \mathrm{~s}^{-1}$ compared with the $300 \mathrm{~m} \mathrm{~s}^{-1}$ for the others. If these 14 events are weaker they are less likely to travel until 19:00 LT.

Finally a few general comments can be made for this investigation. For the events LS-TID energies at both auroral zones are expected to be similar. The existence of some encirclements means that propagation modes over the poles exist. For each event involving a riometer absorption and a substorm onset, LS-TIDs travel towards the equator and later over the poles. For each LS-TID travelling in one direction, a complementary LS-TID of comparable magnitude can be expected to exist travelling in the opposite direction.

Acknowledgements. Topical Editor P.-L. Blelly thanks two anonymous referees for their help in evaluating this paper.

\section{References}

Bartels, J., Romana, A., and Veldkamp, J.: Geomagnetic data 1958, 1959, 1960, rapid variations, Association of geomagnetism and aeronomy, International union of Geodesy and Geophysics, 1962-1964.

Bowman, G. G.: Travelling disturbances associated with ionospheric storms, J. Atmos. Terr. Phys., 27, 1247-261, 1965.

Bowman, G. G.: A relationship between polar magnetic substorms, ionospheric height rises and the occurrence of spread-F, J. Atmos.Terr. Phys., 40, 713-722, 1978.

Bowman, G. G.: Ionospheric frequency spread and its relationship with range spread in mid-latitude regions, J. Geophys. Res. 96, 9745-9753, 1991.

Bowman, G. G.: Some aspects of large-scale travelling ionospheric disturbances, Planet. Space Sci., 40, 829-845, 1992a.

Bowman, G. G.: Some aspects of mid-latitude daytime ionospheric disturbances, J. Atmos. Terr. Phys., 54, 1513-1521, 1992 b.

Bowman, G. G. and Mortimer, I. K.: Some characteristics of large-scale travelling ionospheric disturbances and a relationship between the $F_{2}$ layer height rises of these disturbances and equatorial pre-sunrise events, Ann. Geophys., 28, 1419-1430, doi:10.5194/angeo-28-1419-2010, 2010. 
Bowman, G. G. and Shrestha, K. L.: Ionospheric storms and small pressure fluctuations at ground level, Nature, 210, 1032-1034, 1966.

Chan, K. L. and Villard, O. G. J.: Observations of large-scale traveling Ionospheric Disturbances by Spaced-Path High-Frequency Measurements, J. Geophys. Res., 67, 978-988, 1962.

Ding, F., Wam, W., Ning, B., and Wang, M.: Large-scale travelling ionospheric disturbances observed by GPS total electron content during the magnetic storm of 29-30 October, 2003, J. Geophys. Res., 112, A06309, doi:10.1029/2006JA012013, 2007.

Ding, F., Wam, W., Liu, L., Afraimovich, E. L., Voeykov, S. V., and Perevalova, N. P.: A statistical study of large-scale traveling ionosperic disturbances observed by GPS TEC during major magnetic storms over the years 2003-2005, J. Geophys. Res., 113, A00A01, doi:101029/2008JA013037, 2008.

Francis, S. H.: Global propagation of atmospheric gravity waves: A review, J. Atmos. Terr. Phys., 37, 1011-1054, 1975.

Hajkowicz, L. A.: Conjugate effects in the generation of travelling ionospheric disturbances (TIDs) in the F region, Planet. Space Sci., 31, 1409-1413, 1983a.
Hajkowicz, L. A.: Auroal riometer absorptions and the F-region disturbances observed over a wide range of latitudes, J. Atmos. Terr. Phys., 73, 175-179, 1983b.

Hajkowicz, L. A.: The dynamics of a steep onset in the conjugate auroral riometer absorption, Planet. Space Sci., 38, 127-134, 1990.

Heisler, L. H.: Observation of movement of perturbations in the $\mathrm{F}$ region, J. Atmos. Terr. Phys., 25, 71-86, 1963.

Karpachev, A. T., Deminova, G. F., Beloff, N., Carozzi, T. D., Demisenko, P. F., Karhumen, T. J. T., and Lester, M.: Global pattern of the ionospheric response to large-scale gravity waves, J. Atmos. Sol.-Terr. Phys., 69, 906-924, 2007.

Khan, M. S. H.: Sporadic E structures and pressure oscillations at ground level, Aust. J. Phys., 23, 719-730, 1970.

Lei, J., Burns, A. G., Tsugawa, T., Wang, W., Solomon, S. C., and Wiltberger, M.: Observations and simulations of quasiperiodic ionospheric oscillations and large-scale traveling ionospheric disturbances during the December 2006 geomagnetic storm, J. Geophys. Res., 113, AO6310, doi:10.1029/2008JA013090, 2008. 